\title{
Top 7 Issues in Medical Tourism: Challenges, Knowledge Gaps, and Future Directions for Research and Policy Development
}

\author{
Jason Behrmann (Corresponding author) \\ Programmes de Bioéthique, Département de médecine sociale et préventive \\ Université de Montréal, C.P. 6128, succursale centre-ville \\ Pav. Margeurite d'Youville (7e étage) \\ Montréal (Québec), Canada, H3C 3J7 \\ Tel: (514)-343-6111 x $4881 \quad$ E-mail: jason.behrmann@umontreal.ca
}

Elise Smith

Programmes de Bioéthique, Département de médecine sociale et préventive

Université de Montréal, Montréal, Canada

C.P. 6128, succursale centre-ville

Pav. Margeurite d'Youville (7e étage)

Montréal (Québec), Canada, H3C 3J7

Tel: (514)-343-6111 x 4881 E-mail: elise.smith@umontreal.ca

The authors are supported by fellowships and scholarships from the Université de Montréal, the Social Sciences and Humanities Research Council of Canada (SSHRC), and the Canadian Institutes of Health Research (CIHR).

\begin{abstract}
Medical tourism is a general term that describes patients traveling to obtain health services. The growth of medical tourism is due to a broad range of motivators and increasingly, developing countries are seeking to capitalize on these flows and are linking medical care with actual tourist activities. This commercial linkage between healthcare and tourism is a rapidly developing and profitable industry that is attracting growing interest amongst health researchers. This article summarizes seven leading issues concerning medically-motivated travel that were identified by academic researchers during a November 2009 Symposium on the Implications of Medical Tourism for Canadian Health and Health Policy. These issues include emerging technologies, particular vulnerable populations, Canadian business ties to the industry, patient populations excluded from analysis, and comparative analyses between health service providers for medical travelers. This article aims to help guide researchers as they investigate ethical, legal, social, public health, and economic issues related to the growing medical tourism industry.
\end{abstract}

Keywords: Medical tourism, Strategic research, Health policy, Guidance

\section{Introduction}

In November 2009, the University of Ottawa Globalization and Health Equity Research Unit held the Symposium on the Implications of Medical Tourism for Canadian Health and Health Policy ("Symposium on the Implications of Medical Tourism for Canadian Health and Health Policy," 2009) (abbreviated hereafter as, the Symposium), sponsored by the Institute of Health Services and Policy Research (IHSPR) of the Canadian Institutes of Health Research (CIHR). Twelve leading researchers from a variety of scholarly disciplines including bioethics, public health, health policy, geography, health sciences and women's studies convened for a series of presentations and exchanges (Note 1). Numerous topics and issues concerning medical tourism and Canadian health policy were identified in the course of the Symposium, discussions which considered broad overviews, focused studies, summaries of ongoing research projects, and case studies concerning medical tourism (Note 2). At the end of the Symposium, a plenary discussion explored the current challenges and knowledge gaps pertaining to medical tourism, as well as tentative strategies on how best to advance research initiatives and investigate this emerging industry. 
This article summarizes the findings of that plenary discussion as rendered by the authors of this work (thus, this article does not constitute as a position statement of the Symposium participants themselves). We begin our discussion by providing a contextual overview of the medical tourism industry, and follow with a discussion of seven promising areas for further research as identified by the Symposium participants. While this article does not present empirical findings from a specific research initiative, it does synthesize existing knowledge and identify gaps in scholarship, which the authors believe could serve as a guide for Canadian researchers in conducting their own independent investigations into the medical tourism industry.

\section{Background}

While not a new topic, medical tourism has received increased media attention in recent years due in part to the growing number of Canadians seeking healthcare abroad (CBC, 2004; Eggertson, 2006). Several key factors have been suggested to explain the growing phenomenon of medical tourism, including: soaring healthcare costs in some industrialized nations, notably the United States; longer wait times for medical procedures in countries such as Canada and the United Kingdom; and desire to gain access to services that are unavailable locally, such as innovative surgical techniques not yet approved by public or private insurance schemes.

While it is impossible to predict the future of medical tourism with absolute certainty, there is evidence to suggest that it will continue to grow in both developed and developing countries. First, a growing number of hospitals in lower-income countries such as India are obtaining international medical accreditation as a means to help allay medical travelers' concerns about the quality of health services available in the developing world ("Medical tourism: Consumers in search of value," 2008). Second, and more specific to European countries, a European Union Commission Directive has been introduced to address cross-border medical travel by clarifying the rights of patients obtaining healthcare in EU countries other then their country of residence (Healy, 2009; Hermesse, Lewalle, \& Palm, 1997). Additionally, the number of countries that are developing their own medical tourism industries has increased, and so the provision of health services to foreigners for profit is becoming a highly competitive market. For example, wealthy individuals from developing nations have tended to seek care in North American and Western European nations, but this pattern is shifting to other developing countries (Kangas, 2007; Lautier, 2008), notably the United Arab Emirates, Jordan, Thailand, Singapore, and Tunisia, nations with increasingly sophisticated medical infrastructure and lower comparable costs in healthcare.

The industry also appears to be developing regional hubs that strategically cater services to potential tourists in proximity. For example, Latin American and Caribbean medical travelers demonstrate a preference for Cuba and Chile as popular medical destinations (Charatan, 2001; Cortez, 2008). Overall, many destination countries are aggressively marketing their medical tourism industry along with sophisticated promotional strategies that emphasize the affordability, high-quality and prompt access to their health services. One noteworthy example is India, where national policies support advertisements (CBC, 2009b) that target Canadian patients in conjunction with the development of trade treaties that aim to obtain coverage by private or public insurance schemes for care within their accredited facilities (IMTA, 2009).

This brief introduction to the medical tourism industry illustrates that the international provision of health services to Canadian patients is changing at an appreciable rate and occurring within an increasingly integrated global marketplace. Current trends raise important questions concerning present and future health policy implications. Will this rapid change and globalization of commercialized health services result in improvements for Canadian healthcare and population health? If not, why not? And what practical steps can Canadian policy-makers take to avoid foreseeable negative outcomes stemming from the development of this industry? Answers to these questions will emerge from future research into the specific features of medical tourism. The following sections offer expert opinions concerning the 'next step forward' in medical tourism research by highlighting emerging issues of importance to Canadian academics and policy analysts.

\section{Discussion: What we do Not-and Should—Know About Medical Tourism}

\subsection{Abroad and at Home: Implication of Canadian Enterprises in Medical Tourism}

Efforts aimed towards regulating the global medical tourism industry — in whatever form they may take - will undoubtedly face significant challenges. For one, government bodies have limited abilities to enforce regulations in jurisdictions beyond their national boundaries. Coupled with the fact that people with the necessary travel documents are free to travel internationally, it is thus unlikely that legislation enacted within Canada could have a significant impact on the actions of both Canadian medical tourists abroad as well as foreign heath systems. This premise is based on the assumption that medical tourism is a business that happens exclusively abroad. We note, however, that this is not always the case. 
Medical tourism is similar to many contemporary industrial sectors in terms of globalization (Horowitz, Rosensweig, \& Jones, 2007), defined here as the growing interconnectedness of transnational economies. Many companies strategically fragment their operations, such that a head office will reside in a nation with, say, a well-developed infrastructure, while its manufacturing sector may be outsourced to a nation with lower labour costs. Though medical procedures and health services are typically performed abroad, important sectors of medical tourism companies (e.g., administration), do exist on Canadian soil.

An example of a Canadian-based office of an international medical tourism enterprise was identified in a study examining reproductive tourism in Argentina (Smith, Behrmann, Martin, \& Williams-Jones, 2010). While the private clinic, Go Sculptura, provides all medical services (ranging from plastic surgery, fertility treatments, and gastric bypass surgery) abroad, the authors observed that the company's website ("Go Sculptura Contact Page/Spanish ", 2010) lists their "home office mailing address" in Montréal, Québec. Furthermore, a report published by Herrick (2007) demonstrates that a collection of private insurance companies are offering insurance policies that compensate medical tourists in the event of malpractice, where some of these insurance claims are administered by independent, Canadian-based firms. Moreover, Turner (2007b) has identified an additional 15 companies located across Canada that arrange medical tourism vacation packages. In some respects these businesses provide services that resemble the services offered by travel agencies specializing in traditional "holiday" travel.

The preceding examples demonstrate that Canadian enterprise is implicated in the medical tourism industry in several ways. This finding is of particular significance to the initial topic of this section: Regulation. While there are many challenges to regulating activities beyond national borders, legislators can exercise significant control over business activities conducted locally, i.e., on Canadian soil. Future efforts to regulate medical travel should begin by focusing on these Canadian sectors of the industry. For example, legislation could stipulate that private malpractice insurance can only be sold to Canadian tourists if they obtain health services at a reputable facility with proven measures of quality and safety. This tentative regulatory strategy indicates that future research initiatives that aim to identify Canadian business ties to medical tourism would likely be of significant interest to health policy analysts. Overall, while most aspects of medical tourism happen abroad, identifying the minority of activities conducted on Canadian soil should be a priority for upcoming investigations.

\subsection{The Forgotten Tourists: Do We Ignore Travelers Within Nations, as well as the Movement of Health Professionals?}

Over the last five years, media coverage has focused mostly upon international travel of medical tourists (for an example, see (CBC, 2004)). This is also the main focus in the academic literature, where most definitions and descriptions of medical tourism emphasize the international dimensions of the industry. The definition offered by Conell (2006) is representative: "people travel[ing] often long distances to overseas countries to obtain medical, dental and surgical care". Thus, similar to the previous discussion of businesses involved in medical travel, current descriptions of Canadian medical tourists emphasize movement abroad, and pay little attention to intra-national health-related travel.

This focus on international travel can be considered misleading since many patients, notably in Canada, cross provincial or regional boarders to obtain health services. For example, it is common for women living in remote villages and aboriginal communities to travel to urban areas in order to give birth in a medically supervised environment (Moffitt \& Vollman, 2006; Van Wagner, Epoo, Nastapoka, \& Harney, 2007). There are also instances where province-specific health policies generate provincial differences in access to, and affordability of, health products, such as pharmaceuticals (Sibley \& Glazier, 2009). This in turn motivates many Canadians to acquire medical goods and services by engaging in provincial cross-border travel.

These examples reinforce the fact that medical travel is a national or local phenomenon in Canada as well as international, and the research and policy communities must consider this in their analysis. Analyzing "endogenous medical travel" is relevant to ongoing Canadian health policy debates. Investigations into the underlying motives for endogenous medical travel can identify current weaknesses in the Canadian healthcare system and limitations in current health legislation. The Canada Health Act ("Canada Health Act," 1999) is a useful example. The Act stipulates that essential health services must be accessible to all Canadians, regardless of location. The observation that many Canadians must travel in order to obtain these services, however, raises questions as to whether all patients (e.g., disabled people, the financially impoverished) can actually travel to obtain medically necessary services, which in turn identifies important limitations in health legislation and patient rights. When taken as a whole, it is clear that the 'forgotten' endogenous medical travelers should be as important to the research and policy communities as the more sensationalized, cross-border travelers. 
The omissions by academic researchers extend beyond that of specific patient groups. Many health professionals are travelers as well, and indeed they play an important role in the international trade of health services. These professionals, however, are largely excluded from discussions concerning medical travel, and thus represent an overlooked area of study. The international movement of Cuban doctors is one case in point. Originating from unique economic agreements, surplus Cuban physicians have been temporarily relocated to neighbouring countries with deficient health systems, such as Venezuela, in exchange for primary resources, namely petroleum (Alvarado, Martínez, Vivas-Martínez, Gutiérrez, \& Metzger, 2008). This situation represents an interesting contrast to common definitions of medical tourism - it is the doctors who become tourists travelling to foreign patient populations. Note that this situation is for economic benefit much like most 'conventional' forms of medical tourism. Does this "reverse directionality" in the movement of health services raise novel ethical, social, and political concerns? If so, how so? And at a more general level, does the term medical tourism require a redefinition so that it is inclusive of the local and international movement of both patients and health professionals; and perhaps also medical equipment? These are important questions that will need to be addressed in future investigations and academic debates.

\subsection{Heterogeneity in services and service providers}

It is interesting to note that the term medical tourism is evolving. Once used as an umbrella term for the industry as a whole, growing specializations and heterogeneity in services have expanded the lexicon into sub-domains such as reproductive tourism, organ transplant tourism, and abortion tourism. This evolution in terminology reflects the growing diversity and heterogeneity in the medical tourism industry, which we believe can provide an interesting foundation for comparative analyses. To demonstrate this, we will describe the significance of heterogeneity in services and service providers.

While the fact that there is a medical tourism industry raises a variety of matters of interest (e.g., divergent medical standards of quality between host and destination countries), it is important to note that particular services offered within medical tourism sub-domains raise distinct medical, socio-ethical and policy challenges. For instance, travelling to obtain fertility treatment has different implications than those related to cosmetic surgery. For one, complications from cosmetic surgery impact the patient's health and appearance, while complications from fertility treatments (e.g., gestation of multiple embryos and the resulting low-birthweight babies) affect not only the mother, but the fetuses as well and could result in long term complications for the mother and future children long after they return home. The comparisons between these two services suggest that issues related to malpractice and/or responsibilities for medical complications are not equivalent within sub-domains of medical tourism.

Consider another comparison between organ transplant tourism and abortion tourism. The scarcity of donated organs affects a broad range of Canadians in need of a transplant, and the option to obtain an organ from abroad is often determined by one's ability to purchase such health services from the black-market (Turner, 2009). In contrast, abortion tourism is exclusive to women and is typically motivated in countries such as Canada-where access is not legally restricted - by factors such as social stigma (Sethna \& Doull, 2009). From this comparison, it is apparent that sub-domains in medical tourism can be relevant to particular population groups in exclusivity, and can be motivated by radically different factors. Furthermore, certain categories of medical tourism are inherently unlawful since they involve the purchase of services from the black-market. Such differences identify notable areas for potential ethical concern, targeted policy development, and the need to understand underlying social and medical factors that encourage medical tourism.

Moving beyond comparisons between health services, researchers should also be aware that comparisons between service providers could identify important issues for investigation. This possibility is made evident from an analysis into the heterogeneity in service providers for fertility treatments in Argentina (Smith, et al., 2010). While several private fertility clinics offer services to tourists, these clinics are non-equivalent in terms of regulatory oversight. To expand, a majority of these clinics are certified as "accredited facilities", meaning that government organizations collaborate with these facilities in order to certify that health services are conducted according to established standards of quality and safety. A minority of private clinics, which aggressively market their services to tourists, are non-accredited, thus demarcating an important distinction in the regulatory oversight of private clinics within Argentina. While this study focused on fertility clinics in Argentina, it is important to note that heterogeneity in health service providers is a growing phenomenon in medical tourism around the globe (i.e., increasing - but not ubiquitous - government certification of private hospitals in India and Thailand that meet international medical standards of quality and safety (Marlowe \& Sullivan, 2007)). 
Examining differences between medical facilities for tourists is significant for many reasons. At a broader level, academic researchers might be mislead in analyzing health service providers for medical tourists as being differentiated solely by general characteristics, such as region, and otherwise assume providers to be roughly equivalent within the general category. Furthermore, cross-analysis of different service providers might provide a better understanding of the diversity of access to and quality of care within particular categories of medical tourism. Indeed, with the evolving nature of the medical tourism industry, it appears that future research investigations will likely identify topics of significant interest by studying the 'devil in the details' of service provision. To conclude this section, the key point is that researchers should scrutinize the growing heterogeneity in medical tourism since comparative analyses between both services and services providers can identify unique aspects of medical tourism that deserve particular regulatory or policy attention.

\subsection{Patient Perspectives, Motivations, and Outcomes: Anecdotal versus Empirical}

Several factors that motivate patients to travel in the pursuit of health services are noted in the academic literature. Most of these reported motivations appear obvious and are thus assumed, prime examples being the pursuit of lower costs for or greater access to healthcare. In addition to motivations, many popular destinations for medical tourists appear well founded and are reported in the academic literature. Rigorous empirical data on medically-motivated travel, however, is limited; and this applies particularly to Canadians seeking healthcare abroad. Provincial data exist for the number of Canadians who are authorized by their public health insurance plan for out-of-country medical care, but data on self-chosen medical travel or for out-of-country care not reimbursed by provincial plans remain sparse and incomplete (Turner, 2007a). Moreover, although there is evidence of Canadians seeking care in developing countries, robust accounts of patient motivations and their destinations are lacking. Little is known of the resulting health outcomes of medical tourism (e.g., patient satisfaction, incidence of complications), data that is essential for debates concerning the risks and benefits of medically-motivated travel. Overall, it is apparent that most of the discussion of the pros and cons of medical tourism are based on anecdotal evidence, questionable estimates and projections, or theory-based assumptions that, while useful, lack empirical validation (Crooks, 2009). For Canadian regulators to develop robust and sound health policies concerning medical travel, this knowledge base will need to move towards a more solid empirical foundation. The need for more empirical findings highlights a significant knowledge gap as well as promising areas for future research. As a further endorsement of this research initiative, a brief proposal for empirical economic analysis of medical tourist destinations will conclude this section.

One main purported benefit of the medical tourism industry is that it provides a lucrative source of income for developing world economies (Goodrich, 1993). However, a corollary critique is that the industry is unlikely to improve population health and access to healthcare for the majority of impoverished peoples within these nations (Turner, 2007a). To expand, the lucrative medical tourism market may encourage health professionals and governments to focus their careers and resources towards private facilities that treat the needs of foreigners. Such a development risks compounding existing health inequalities both locally (between rich and poor) and between the developed and developing world. A counterargument to this critique is that the injection of foreign capital into local economies as a result of medical tourism will in turn generate jobs, increase the tax base, and thus improve the aggregate level of social and economic wellbeing with eventual positive health externalities.

Which of these scenarios is most credible remains to be established; and whether the second scenario (aggregate welfare gain) leads to reduction in health inequalities within destination countries depends on state policies to tax such gains for programs (transfers, services) that are deliberately redistributive in design. Detailed economic assessments are required to establish broad social benefits and harms flowing from transnational medical travel. Of particular significance are empirical measures of the profits generated by healthcare institutions catering to foreigners and comparing that figure to the amount of revenue that actually enters as government revenue. These empirical economic measures merit priority in future research endeavors since they will provide objective data to establish whether medical tourism by Canadian patients indeed provides a net benefit for both Canadians and the communities that host these patient-visitors.

The methodology for such analyses involves relatively straightforward accounting. However, gaining access to the financial records of private companies in foreign nations will be challenging. Therefore, tentative strategies for economic assessments should include policy developments that would make such financial data accessible to researchers. For example, provincial governments could mandate through bilateral treaties that public funds will subsidize medical travel only if Canadian patients obtain care at foreign institutions that provide a degree of transparency with their financial records. And, in keeping with Canada's principles of universality, these treaties could stipulate that these foreign institutions must show how transfers of public revenues from Canadian health 
insurance programs support more equitable access to healthcare across population groups in the destination country.

\subsection{Vulnerable Populations and Inequities}

When analyzing the cross-border movement of patients seeking out-of-pocket health services, it is reasonable for researchers to investigate the underlying economic and political factors that promote this phenomenon. Indeed, a significant number of procedures undergone by Canadian medical tourists (e.g., hip replacements, cataract surgery) are obtainable - and often publically subsidized - in Canada, but are not readily available due to lengthy wait times. Many other procedures sought-out by medical tourists are also available in Canada, but often require significant personal expenditures (e.g., dental and cosmetic surgery). These observations may lead observers to conclude that medically-motivated travel is often reducible to issues of cost and access. However, researchers need to be aware that these assumptions are generalizations that can inadvertently distract focus away from broader issues associated with medical travel, such as motivations for travel associated with particular conditions of vulnerability or inequities in healthcare access, despite the universality of the Canadian healthcare system.

Are there factors of Canadian society that encourage - and possibly even necessitate - that particular population segments engage in medically-motivated travel? The answer to this question remains unclear and merits further investigation. Some evidence, however, suggests that particular vulnerabilities correlate with medical tourism. For example, segments of the female population are known to be particularly vulnerable in their abilities to control their reproductive health, and specifically, terminate an unwanted pregnancy if they so choose (Jewell \& Brown, 2000; Sethna \& Doull, 2009). Despite abortion being legal in Canada, many women remain vulnerable by the fact that cultural taboos, religious ideologies, and social stigma can make abortion services unavailable or impractical in their communities (Eggertson, 2001). Moreover, the aforementioned social factors influence many politicians to avoid addressing this politically charged issue and ensuring that abortion services are widely accessible. It is important to note that in this situation, the determining factors for abortion tourism are thus entrenched in social and political mores and beliefs that render some women vulnerable to political neglect of their reproductive needs with consequent limited access to this specific health service.

A closely related topic to conditions of vulnerability is how social inequities can prompt medical travel. Access to fertility treatments by minority groups is one pertinent example. Technically, the primary limiting factor in receiving treatment from a private clinic is the ability to pay. However, this is not always the case. A survey (Gurmankin, Caplan, \& Braverman, 2005) of private American fertility clinics demonstrates that there is no formal legislation or consensus amongst service providers that outlines which patients can receive treatment. Therefore, choice in service provision is decided by individual clinics, where some facilities openly deny treatment to certain population groups, such as would-be single mothers and lesbian couples (Gurmankin, et al., 2005). While the underlying reasons as to why certain clinics deny services to these minority groups is not stated, it is reasonable to assume that prejudice and unjust discrimination have a role in this patient selection process. One can speculate reasonably that these inequities in service provision may in turn motivate patients to seek treatment in other jurisdictions where social perceptions are not limiting factors. In sum, neither treatment costs, wait times, nor unavailability of services are necessarily the root factors underlying all medically-motivated travel. Rather, the research and health policy communities should be cognizant that medical tourism can also arise from existing social inequities or stigma affecting particular patient populations.

\subsection{Emerging Technologies}

Medical tourism is a growing industry both in terms of popularity and in the diversity of available medical interventions offered by foreign clinics (e.g., reproductive technologies, organ transplantation, pharmaceutical drugs). The term 'available' is key - technological advancements in biomedicine will undoubtedly contribute to the growing array of services obtainable by medical tourists, especially when some countries with slight oversight are likely to introduce novel technologies more rapidly than countries that subject new procedures to detailed regulatory investigations. Due to this possibility, an interesting area of future research scrutiny will be how, and what, technological innovations may influence the medical tourism industry of tomorrow. We discuss two emerging technologies that serve as examples, one hypothetical and the other actual.

The first example of a technological innovation is genetic transfer. Unlike genetic modification, which signifies introducing a complete and stable genetic alteration in an entire organism, genetic transfer is a transient and localized genetic modification, usually of a given tissue. For example, plasmids containing a gene of interest are injected into muscle tissue so that muscle cells uptake the plasmid and express the foreign gene for a period of days, sometimes weeks, until the plasmid is finally degraded. Medical applications for genetic transfer remain limited; however, this technology could provide novel means to inoculate individuals against pathogens and 
allergic hypersensitivities (Behrmann, 2007). This technology also raises concern since it could be used for non-health related enhancements, and some experts claim that this technology will be the "new steroids" for elite athletes who engage in "gene doping" (Haisma \& de Hon, 2006). To expand, a marathon runner could obtain a competitive advantage by having their leg muscles injected with a gene that mitigates the effects of exercise-induced oxidative stress. The negative sentiments by both the public and professional organizations towards cheating in sport will likely push the provision of gene doping underground, or to nations that chose not to ban the practice. Thus, a new sector within the medical tourism industry may emerge as the technique of genetic transfer aimed at controversial enhancement purposes - for athletics or otherwise - reaches maturity.

While genetic transfer might become a draw for tourists in the future, the second example of a novel technological innovation has recently spurred a flurry of Canadian patients anxious to obtain a controversial medical procedure abroad: vein expansion as a treatment for multiple sclerosis (MS) (CBC, 2009a, 2010). Presently in the very early stages of clinical assessment, little evidence exists concerning the safety and efficacy of this experimental surgical procedure. Access to the medical intervention remains limited to a collection of hospitals outside of Canada, and the procedure must be paid for out-of-pocket. Despite these hurdles, many desperately ill MS patients have gone abroad in order to have the procedure. The experiences of Canadian (and other) MS patients demonstrates how sudden advancements in biomedical sciences can induce medically-motivated travel. Research and health policy communities should thus be aware that technological innovation is intertwined with - and perhaps predictive of - the future development of the medical tourism industry. Furthermore, as the medical tourism industry is rapidly expanding within the developing world, so too is the biotechnology industry (Thorsteinsdottir, Quach, Daar, \& Singer, 2004), and the developing world may likely emerge as a significant contributor to biomedical innovation. Indeed, it would be interesting to investigate how the development of one industry might influence the other in these nations.

\subsection{Human Tissues and Organs: Meeting Health Needs or Commodifying Populations?}

Resource scarcity within the health sector is not exclusive to monetary constraints. Also significant are limitations in the number of human tissues and organs available for transplant, which in turn prevent access to potentially life-saving treatments for many Canadian patients. What may be scarce in one country, however, may be abundant in another, especially in contexts where desperately poor individuals may be all too often eager (having little other choices available) to sell a piece of their bodies as a means to afford their basic needs (Dickenson, 2005; T. Harrison, 1999). This section aims to inform the academic and health policy communities of how medical tourism can have a significant influence in the commodification of human tissues and the ethical concerns this economic reality will entail. Additionally, this section notes that researchers should be aware that the availability of particular tissues, such as human gametes, could serve as a tool to predict the future development of the medical tourism industry in particular regions of the globe.

Advances within the biomedical sciences have drastically expanded treatment options for numerous diseases; however, this scientific progress has also raised ethically contentious issues related to the commodification of human tissues and body parts (Nelkin \& Andrews, 1998). Once discarded as medical waste, umbilical cords are now precious sources of stem cells, and excised tumors have become valuable tools in research; even genetic sequences are now patentable entities. Though a full description of the ethical implications is beyond the scope of this article, the transformation of human tissues into marketable goods has several ramifications. In brief, the commodification of such materials raises concerns related to the exploitation of peoples who provide the tissues, the association of monetary values to particular individuals and not others, and the increasing ownership of genes and cell lines that many believe should remain as universally shared components of humanity, amongst others (Dickenson, 2005; C. H. Harrison, 2002). Concerns stemming from the commodification of human materials of biomedical value are well known and aggressively debated. Stemming from these discussions, safeguards that mitigate these concerns are now present or in development, such as legislation that protect tissue donors from financial exploitation (C. H. Harrison, 2002) or the oversight of research projects involving human subjects to ensure that tissues are obtained through voluntary, informed donations or with adequate compensation (Siminoff, Arnold, Caplan, Virnig, \& Seltzer, 1995). The same cannot be said of another, equally important factor that is encouraging the commodification of human materials, that is, the medical tourism industry and in particular the sale of human organs.

The global shortage of donated cadaveric organs has motivated the medical community to procure, where medically possible, organs from living donors (Barr et al., 2006). Despite increases in numbers of organs provided by living donors, severe shortages remain. The gap between supply and demand for organ transplants has encouraged some individuals with sufficient economic resources to travel to countries where organs are available for purchase (Turner, 2009). These arrangements commonly occur in settings with high levels of 
corruption, poorly regulated medical facilities and healthcare professionals, and extreme poverty. In such contexts, organ trafficking is typically illegal but buying, selling, and brokering human organs occurs. Organ sellers often engage in commercial transactions where they are not informed of the possible consequences of their actions; some donors willingly sell an organ for as little as $\$ 1200$, thus it should be obvious that in such cases organ sellers are routinely being exploited by professionals in the organ transplant tourism industry. When analyzed from a broader perspective, it is apparent that effective legislation (national or international) to protect individuals from organ exploitation is virtually non-existent, or not enforced. Moreover, debates centering on how to address the ethically contentious nature of buying organs from vulnerable populations are still in their infancy.

The current option to purchase an organ illegally from overseas will likely become even more popular with the passage of time since the priority list for recipients of organ transplants remains long and the shortage of donated organs shows little sign of improving (Kondro, 2006). While biomedical research is known to have a significant influence in the commodification of human tissues, the research and health policy communities must be aware that medical tourism might play an equally important role in the future commodification of the human body. This reality also highlights that the issue of medical tourism and commodification merits further research and debate in order to raise current knowledge of the subject to a level equal to that of ongoing debates concerning commodification due to advancements in the biomedical sciences. In fact, since organ transplant tourism inevitably requires the exploitation of the most poor and vulnerable populations of the globe, further research into this phenomenon is imperative.

The highly contentious issues associated with the black-market sale of human organs are quite clear. What may be less obvious to researchers is that the sale of minute quantities of human tissues, even when it constitutes a single cell, can raise questions of equal concern. The sale of human gametes (Dickenson, 2002) in the reproductive tourism industry is a notable case in point. While several countries currently offer affordable assisted reproductive medical services to tourists, an intriguing question is whether the phenotypic characteristics of a population, such as race, can favour the development of this industry in particular countries. An interrelated question is whether this 'racial-advantage' can in turn be morally problematic.

To expand, one study (Smith, et al., 2010) observed that some private fertility clinics in Argentina that cater to medical tourists offer the sale of human gametes in their list of assisted reproductive services. Considering that many medical tourists seeking fertility treatments are from the developed world and of Caucasian decent, could Argentina (with its dominant population constituted from European immigrants (Luna, 2002)) have an advantage in attracting prospective tourists relative to other countries?

The fact that reproductive tourists might be drawn to a particular country based on the availability of gametes obtained from a population of a defined race is not morally problematic per se; it is arguably defensible for parents to want their child to have a similar physical appearance to their own if they so choose. This issue becomes contentious, however, when gametes of a defined phenotype become limited and prized commodities for reproductive tourists, where economic laws of supply and demand then encourage price differentials based on race. Indeed, many would likely find the sale of human tissues that give more monetary value to a particular race to be morally indefensible. Thus, it is of considerable interest for future investigations to scrutinize whether the growing medical tourism industry will further globalize the market in human tissues and encourage ethically contentious associations between monetary value and particular human traits. Policy analysts will need to devise strategies to ensure a more ethical pricing and sale of human tissues throughout the globe; at a minimum, such efforts are essential for the reputation of the industry as a whole. In addition to ethical concerns, the above example demonstrates that researchers may be able to foresee the future development of the industry in specific regions of the globe based on the sale of human tissues and particular population characteristics of nations hosting medical tourists.

\section{Conclusion}

This article represents a collection of expert opinions by academic researchers from diverse disciplines, the goal of which was the identification of important knowledge gaps, current challenges, and strategic areas for future research into medical tourism and its relationship with Canadian health policy. Many of the issues raised in this article are pertinent to future regulatory efforts, such as the need to identify Canadian enterprises implicated in medical tourism and a need for greater attention towards endogenous medically-motivated travel within Canada. Other subjects highlighted in our paper include strategies for identifying important ethical and policy challenges associated with medical tourism, such as analyzing the growing heterogeneity of the industry. Comparative analyses between services, such as organ transplant and abortion, or between service providers, such as 
accredited and non-accredited clinics, are exemplified as subjects for comparisons. Another important topic of investigation pertains to the future development of the medical tourism industry. In particular, scrutinizing emerging biomedical technologies and the availability of human tissues is proposed as a framework in predicting tentative characteristics of the medical tourism industry of tomorrow. This article also underscores the need for research to determine how the industry is related to the vulnerability of populations and how broader social factors pressure certain members of society to seek healthcare abroad. Finally, this article calls attention to the need for generating more empirical data that measures the underlying motives for and consequences of medically-motivated travel.

Whether one is "for" or "against" medical tourism, if current trends continue, this industry will undoubtedly play an increasingly important role in the provision of health services to Canadians. It is in our best interest to understand the intricate details of this industry. Only then will we be able to support potential benefits and avoid foreseeable harms, for both Canadians and the communities that play host to our medical travelers. This article presents seven major issues that merit further investigation by the Canadian research and health policy communities. While these seven issues are not an exhaustive list of all pertinent topics related to medical tourism, they can serve as a foundation for promising research initiatives that will arise in the near future.

\section{Acknowledgements}

The authors would like to express deep gratitude to all the participants at the Symposium at the University of Ottawa

www.globalhealthequity.ca/electronic\%20library/Medical\%20Tourism\%20Symposium\%2013\%20Nov\%202009 \%20Final\%20Program.pdf). Many thanks are extended to Dr. Bryn Williams-Jones of the Université de Montréal, Leigh Turner of the University of Minnesota, and Dr. Ronald Labonté of the University of Ottawa, for helpful comments and edits concerning preliminary drafts of this article. Turner and Labonté, as well as Drs. Christabelle Sethna and Marion Doull of the University of Ottawa, provided $1 / 2-2$ page abstracts concerning their areas of expertise concerning research into the medical tourism industry. These abstracts were helpful in developing and organizing the ideas presented in several sections of the article (specifically, Turner: organ-transplant tourism; Labonté: background information; Sethna and Doull: abortion tourism).

\section{Conflicts of Interest}

The authors declare no competing interests.

\section{Notes}

Note 1. The following is a listing of members who actively participated at the Symposium (names appear in no particular order): Ronald Labonté, Laura Hopkins, Mohamed Jamal Alsharif, Abdullahel Hadi, Chantal Blouin, Corinne Packer, Valorie Crooks, Raywat Deonandan, Leigh Turner, Christabelle Sethna, Elise Smith, and Jason Behrmann.

Note 2. In addition to this symposium, from the $25^{\text {th }}$ and $26^{\text {th }}$ of June 2010, Simon-Fraser University hosted the International Conference on Ethical Issues in Medical Tourism, also sponsored by CIHR. This conference brought into question "whether medical tourism is ethically defensible and, if not, whether reforms and regulations would make it so" ("Conference web page call for abstracts: Ethical issues in Medical Tourism ", 2010) . Together, these symposiums exemplify the increasing research investment and academic interest within Canada regarding the medical tourism industry.

\section{References}

Alvarado, C. H., Martínez, M. E., Vivas-Martínez, S., Gutiérrez, N. J., \& Metzger, W. (2008). Social Change and Health Policy in Venezuela. Social Medicine, 3(2), 95-109.

Barr, M. L., Belghiti, J., Villamil, F. G., Pomfret, E. A., Sutherland, D. S., Gruessner, R. W., et al. (2006). A Report of the Vancouver Forum on the Care of the Live Organ Donor: Lung, Liver, Pancreas, and Intestine Data and Medical Guidelines. Transplantation, 81(10), 1373-1385 1310.1097/1301.tp.0000216825.0000256841.cd.

Behrmann, J. (2007). Looking ahead at the potential benefits of biotechnology-derived allergen therapeutics. Clin Mol Allergy, $5,3$.

Canada Health Act. (1999). In E.-H. W. Kluge (Ed.), Readings in Biomedical Ethics--A Canadian Focus (2nd ed., pp. 50-55). Scarborough, Ontario: Prentice Hall Allyn and Bacon Canada.

CBC. (2004). Medical tourism: Need surgery, will travel. Indepth: Health Care Retrieved March, 2010, from http://www.cbc.ca/news/background/healthcare/medicaltourism.html 
CBC. (2009a). MS vein theory creates 'huge hope': doctor. CBC News Retrieved April, 2010, from http://www.cbc.ca/health/story/2009/12/15/multiple-sclerosis-veins-buffalo.html?ref=rss

CBC. (2009b). Trade show pitches surgical passages to India. Retrieved March, 2010, from http://www.cbc.ca/health/story/2009/11/20/medical-tourism-trade-show-toronto.html

CBC. (2010). MS vein surgery innovator urges caution. CBC News Retrieved May, 2010, from http://www.cbc.ca/health/story/2010/04/14/mutliple-sclerosis-ccsvi-zamboni-zivadinov-veins.html

Charatan, F. (2001). Foreigners flock to Cuba for medical care. BMJ, 322(7296), 1198.

Conference web page call for abstracts: Ethical issues in Medical Tourism (2010). Retrieved April, 2010, from http://www.fhs.sfu.ca/news/events/cfa-ethical-issues-in-medical-tourism

Connell, J. (2006). Medical tourism: Sea, sun, sand and surgery. Tourism Management, 27, 1093-1100.

Cortez, N. (2008). Patients without borders: the emerging global market for patients and the evolution of modern health care. Indiana Law Journal, 83(1), 71-132.

Crooks, V. A. (2009). An Ethics Approach to Canadians' Decision-Making in Medical Tourism. Retrieved November, 2009, from http://www.globalhealthequity.ca/electronic\%20library/V.Crooks\%20(An\%20Ethics\%20Approach\%20to\%20Ca nadians\%20Decision\%20Making).pdf

Dickenson, D. (2002). Commodification of Human Tissue: Implications for Feminist and Development Ethics. Developing World Bioethics, 2, 55-63.

Dickenson, D. (2005). Human tissue and global ethics. Genomics, Society and Policy, 1(1), 41-53.

Eggertson, L. (2001). Abortion services in Canada: a patchwork quilt with many holes. CMAJ, 164, 847-849.

Eggertson, L. (2006). Wait-list weary Canadians seek treatment abroad. Canadian Medical Association Journal, $174(9), 1247$.

Go Sculptura Contact Page/Spanish (2010). Retrieved May, 2010, from http://www.gosculptura.com/spanish/contactGS.php

Goodrich, J. N. (1993). Socialist Cuba: A Study of Health Tourism. Journal of Travel Research, 32(1), 36-41.

Gurmankin, A. D., Caplan, A. L., \& Braverman, A. M. (2005). Screening practices and beliefs of assisted reproductive technology programs. Fertility and Sterility, 83(1), 61-67.

Haisma, H. J., \& de Hon, O. (2006). Gene Doping. Int J Sports Med, 27, 257-266.

Harrison, C. H. (2002). Neither Moore Nor the Market: Alternative Models for Compensating Contributors of Human Tissue. American Journal of Law \& Medicine, 28, 77-105.

Harrison, T. (1999). Globalization and the trade in human body parts. The Canadian Review of Sociology and Anthropology, 36(1), 21-35.

Healy, C. (2009). Surgical tourism and the globalization of healthcare. Ir J Med Sci, 178, 125-127.

Hermesse, J., Lewalle, H., \& Palm, W. (1997). Patient mobility within the European Union. Eur J Public Health, 7(suppl_3), 4-10.

Herrick, D. M. (2007). Medical tourism: Global competition in health care. Dallas, Texas: National Center for Policy Analysis.

Horowitz, M. D., Rosensweig, J. A., \& Jones, C. A. (2007). Medical tourism: globalization of the healthcare marketplace. Medscape General Medicine, 9(4), 33.

IMTA. (2009). Indian Medical Travel Association Home Page. Retrieved April, 2010, from http://www.indianmedicaltravelassociation.com/

Jewell, T. R., \& Brown, R. W. (2000). An economic analysis of abortion: the effect of travel cost on teenagers. The Social Science Journal, 37, 113-124.

Kangas, B. (2007). Hope from abroad in the international medical travel of Yemeni patients. Anthropology \& Medicine, 14(3), 293-305.

Kondro, W. (2006). Fragmented organ donation programs hinder progress. CMAJ, 175(9), $1043-$.

Lautier, M. (2008). Export of health services from developing countries: the case of Tunisia. Soc Sci Med, 67(1), 101-110. 
Luna, F. (2002). Assisted reproductive technology in Latin America: some ethical and sociocultural issues. In E. Vayena, P. J. Rowe \& P. D. Griffin (Eds.), Current Practices and Controversies in Assisted Reproduction (pp. 31-40). Geneva, Switzerland World Health Organization.

Marlowe, J., \& Sullivan, P. (2007). Medical tourism: the ultimate outsourcing: Aon Consulting FORUM.

Medical tourism: Consumers in search of value. (2008). Deloitte Center for Health Solutions Retrieved December, 2009 , from http://www2.deloitte.com/assets/Dcom-UnitedStates/Local\%20Assets/Documents/us chs_MedicalTourismStud $\mathrm{y}(1) . \mathrm{pdf}$

Moffitt, P., \& Vollman, A. (2006). At what cost to health? Tlicho women s medical travel for childbirth. Contemporary Nurse, 22(2), 228-239.

Nelkin, D., \& Andrews, L. (1998). Homo Economicus: Commercialization of Body Tissue in the Age of Biotechnology. The Hastings Center Report, 28(5), 30-39.

Sethna, C., \& Doull, M. (2009). Journeys of Choice? Abortion, Travel and Women's Autonomy. In S. Murray \& D. Holmes (Eds.), Critical Interventions in the Ethics of Healthcare: Challenging the Principle of Autonomy in Bioethics (pp. 179). United Kingdom: Ashgate Publishing.

Sibley, L. M., \& Glazier, R. H. (2009). Reasons for Self-Reported Unmet Healthcare Needs in Canada: A Population-Based Provincial Comparison. Healthcare Policy, 5(1), 87-101.

Siminoff, L. A., Arnold, R. M., Caplan, A. L., Virnig, B. A., \& Seltzer, D. L. (1995). Public Policy Governing Organ and Tissue Procurement in the United States: Results from the National Organ and Tissue Procurement Study. Ann Intern Med, 123, 10-17.

Smith, E., Behrmann, J., Martin, C., \& Williams-Jones, B. (2010). Reproductive Tourism in Argentina: Clinic Accreditation and its Implications for Consumers, Health Professionals and Policy Makers. Developing World Bioethics, 10(2), 59-69.

Symposium on the Implications of Medical Tourism for Canadian Health and Health Policy. (2009). Retrieved April, 2010, from http://www.globalhealthequity.ca/electronic\%20library/medtour.shtml

Thorsteinsdottir, H., Quach, U., Daar, A., \& Singer, P. (2004). Conclusions: promoting biotechnology innovation in developing countries. Nature Biotechnology, 22, DC48-DC52.

Turner, L. (2007a). First World Health Care at Third World Prices?: Globalization, Bioethics and Medical Tourism. BioSocieties, 2(3), 303-325.

Turner, L. (2007b). Medical tourism: Family medicine and international health-related travel. Can Fam Physician, 53(10), 1639-1641.

Turner, L. (2009). Commercial Organ Transplantation in the Philippines. Cambridge Quarterly of Healthcare Ethics, 18(2), 192-196.

Van Wagner, V., Epoo, B., Nastapoka, J., \& Harney, E. (2007). Reclaiming birth, health, and community: midwifery in the inuit villages of Nunavik, Canada. Journal of Midwifery \& Women's Health, 52(4), 384-391. 